\title{
Research on Strategic Analysis and Decision Modeling of Venture Portfolio
}

\author{
Liu Xiaobing ${ }^{1,2, ~ *, ~ T i a n ~ Y i n g j i e ~}{ }^{2}$, Liu Manhong ${ }^{3}$ \\ ${ }^{1}$ College of Management, Shenzhen University, Shenzhen, China \\ ${ }^{2}$ Research Centre on Fictitious Economy and Data Science, University of Chinese Academy of Sciences, Beijing, China \\ ${ }^{3}$ Finance School, Renmin University, Beijing, China
}

Email address:

csulxb2008@163.com (Liu Xiaobing),manniemm@yahoo.com (Liu Manhong), tyj@ucas.ac.cn (Tian yingjie)

${ }^{*}$ Corresponding author

\section{To cite this article:}

Liu Xiaobing, Tian Yingjie, Liu Manhong. Research on Strategic Analysis and Decision Modeling of Venture Portfolio. Journal of Investment and Management. Vol. 7, No. 3, 2018, pp. 91-101. doi: 10.11648/j.jim.20180703.14

Received: June 7, 2018; Accepted: July 30, 2018; Published: August 13, 2018

\begin{abstract}
The value of risk project is usually uncertain, so venture investor must make investment decision based on prior estimation of future value of risk projects. This paper constructs a portfolio optimization model of risk projects considering the psychological characteristics of venture investors, and proposes a Bayesian method to deal with the uncertainty of value estimation in project portfolio selection, and utilizes Monte Carlo method to simulate the model as a linear integer programming problem. The study finds that, compared with portfolio selection based directly on ex ante value estimation, Bayesian modeling of project estimates of project value uncertainty can provide more accurate value estimates and use the resulting revised estimates to make portfolio decisions can help to select a project portfolio with a higher expected utility, eliminate the expected interval between the expected pre-expected utility and the expected utility of post-implementation, and reduce the degree of disappointment of venture investor's expected decision-making.
\end{abstract}

Keywords: Project Portfolio, Loss Disgust, Bayes Modeling, Strategic Analysis

\section{Introduction}

With the intensification of economic globalization and market competition, the investment portfolio of risk projects has become a hot theoretical and practical topic. It is necessary to scientifically make decisions on venture capital investment to improve investment efficiency of venture capital institutions and accelerate the venture capital industry development that has important strategic significance. In actual economic activities, in order to minimize investment risk or maximize investment return, venture capitalists usually invest in different areas, different nature of project portfolio, the purpose is to avoid system risk of project operation or access to higher rate of investment return. If project is not properly selected that will hinder the development of individuals or organizations, and even bring catastrophic losses. Therefore, it is very important for venture capital firms (or venture investors) to allocate limited resources effectively and maximize investment return by selecting and executing project portfolios.

Usually, some projects are chosen based on pre-estimate of how much value they will provide. Estimates on future value of risk projects can be obtained by, for example, net present value calculation, internal rate of return (IRR), cost-benefit study or multi-attribute decision analysis [1-2]. However, at the moment when it is necessary to make an investment decision, the true value of the project is unknown and can only be given a prediction. Obviously, the higher the predicted value, the more likely it is to be selected. In actual investment process, risk project is usually due to the associated or rely on certain uncertain future events and make its future value is uncertain, and venture investors must be given a given resources and other relevant constraints, based on the risk future value of the project is estimated in advance to make investment decisions. In order to reduce uncertainty and improve the decision-making process, venture investors will seek to obtain predictions about the future value of the project from various sources, such as by consulting experts who 
master the data and can obtain a posteriori estimate based on an empirical model. Since these estimates are usually uncertain, there is a random error in predicting the future value of the project, so it is difficult for the venture investor to actually select the portfolio with the highest sum of the ex post value after satisfying the relevant budget and other resource constraints. In particular, even if the ex ante value is estimated to be unbiased, the ex post value of final selected portfolio is likely to be lower than the estimated value of items it contains, namely the selected portfolio probably may be sub-optimal. In other words, at the end of the investment period, when the real value of project is realized, the venture investor may suffer from the so-called post-decision disappointment [3-4].

The existing research on multi-project portfolios is primarily based on mean-risk model. For example, Zhang Qun et al. [5] discussed the establishment of a mean-risk index model for optimal project selection based on expert capital budgeting of project's annual cash inflow and outflow and initial investment expenditure when the historical data was not available. Hall et al. [6] discussed the problem of project selection when there was only partial probability distribution information for the uncertain income of each project, and decision-maker chose a feasible subset of the alternative portfolio so that portfolio income could not reach a given the risk of the target is minimized. Xu Weijun et al. [7] established a multi-project portfolio optimization model with bankruptcy risk constraints under the credibility measure. Yu Chao and Fan Zhiping [8] proposed a multi-industry to consider the decision-maker regret the aversion of venture capital project selection method.

In the field of financial optimization, Bayesian modeling of asset uncertainty has been a long history $[1,9]$. In particular, as a response to recent market information, Bayesian analysis is used to correct model parameters to better predict the price of securities and to further assist investors in making decisions on optimal portfolio of securities [10]. However, securities portfolio optimization and projects portfolio selection are different in many ways. Firstly, the risk project does not have an exact price that can be viewed from the market, and the value of project is usually estimated by the expert's evaluation. Secondly, the decision variable of project investment is a binary $0-1$ variable, namely select or reject [11], while the portfolio of securities can essentially fund the fractional amount of funds for any investment. Finally, although the prices of different securities may be relevant, most of the investment in securities is not logically interdependent. However, in the project investment portfolio, there may be multiple forms of interdependence between projects due to logical relationships. For example, two projects may be mutually exclusive (projects A and B can only choose one) or interdependent (projects A and B can only choose one) or interdependent (if project $\mathrm{B}$ is project $\mathrm{A}$ Subsequent projects, only B can be selected when A is selected. Because of these differences, it is necessary to make a fine analysis of the estimated uncertainty when the project portfolio selection.

Recently, Vilkkumaa et al. [12] demonstrated that Bayesian modeling of the uncertainty of risk project estimates and applying obtained Bayesian correction estimates to the portfolio, compared to direct portfolio selection based on prior value estimates the options can: (1) help to select a portfolio of projects that may be expected to provide higher value for the posterior value; (2) eliminate the expected interval (Gap) between the realized value of the portfolio and the estimated value of previous portfolio, thereby reducing the decision maker may experience the degree of disappointment. However, Vilkkumaa et al. [12] assumed that decision makers are risk neutral and that the decision objective is to maximize the expected value of the project portfolio and to compare the project portfolio with intrinsic value uncertainty without taking into account the risk of the decision maker attitude. Behavioral finance studies have shown that risk appetite of venture investors often affects investment performance and decision-making behavior.

The traditional Von-Neumann expectation utility theory argues that investors' feelings are the same when the amount of earnings and loss of psychological feelings are the same, and the decision-making objective of risk aversion investors is to maximize the expected utility of the end of wealth. Kahneman and Tversky [13] proposed prospect theory (Prospect theory) found that investors are making investment decisions, the concern is the end of wealth relative to a given reference point changes, namely profit or loss, the feeling of investors for the same scale of profit and loss is not the same, more sensitive to loss, namely investors are to avoid loss. In recent years, the discussion of portfolio problems under framework of loss aversion has aroused many researchers' interest [14] For example, Fulga [15] gives a portfolio optimization problem considering the investor's loss of preference in the mean-risk model framework. Jin Xiu and Wang Jia et al. [16, 17] studied the optimal asset allocation and performance of dynamic loss aversion portfolio model. Zhang Maojun et al. [18] study fund managers disgusted investment decision-making from perspective of risk constraints. However, existing portfolio studies based on loss aversion are largely confined to securities market, and research on other types of asset, such as real estate, and general project investment is still rare.

Since the forecast based on historical data or expert assessment of future value of the project in risk environment is usually quite different from the value achieved in the project, this paper that based on the study literature [3, 4, 12] puts forward project optimization by using Bayes method to revise project authenticity and prior estimate. This paper proposes a solution to project portfolio optimization model based on psychological characteristics of venture investors, the model of Monte Carlo method can overcome shortcomings of sample data in some cases by simulating future value of the project. Theoretical analysis and simulation shows that: (1) different from the risk-neutral portfolio model of Simith et al. [3], Chen and Dyer [4] and Vikkumaa et al. [12], this paper discovers that venture capitalist's loss avoidance behavior has an important influence on its portfolio strategy; (2) explicit Bayesian modeling of the uncertainty of estimated value of risk project and applying obtained Bayesian correction 
estimate to portfolio selection can help venture investor to decide investment portfolio that may be expected to provide higher combination of post-utility value, reducing the degree of disappoint of risk venture investors after decision-making, which can decide project portfolio much more effectively. The results of this study can provide a theoretical basis and method for venture investors' portfolio decision making.

\section{Project Investment Decision Model in Risk Environment}

Considering the set of $1, \ldots, m$ alternative projects, the goal of venture investors is to select a subset from these projects to maximize the expected utility value of the selected portfolio under relevant constraints. For example, the total cost of investment cannot exceed the given budget threshold. Other possible constraints include mutual exclusion between projects (for example, select project A only when project B is not selected, and vice versa), or logical dependencies between projects (for example, select item A when only item B is selected). This portfolio selection can be expressed as a decision vector $z=\left[z_{1}, \ldots, z_{m}\right]$ with a $0-1$ element, so that only when project $\mathrm{i}$ is selected $z_{i}=1$.

The real value of the project is $\mathrm{v}=\left[\mathrm{v}_{1}, \ldots, \mathrm{v}_{\mathrm{m}}\right] \mathrm{T}$, which is random variable $\mathrm{V}=\left[\mathrm{V}_{1}, \ldots, \mathrm{V}_{\mathrm{m}}\right]^{\mathrm{T}} \sim \mathrm{f}(\mathrm{v})$. Only when these projects are executed at the end of investment period, they will be realized and observed. In the following part, it is assumed that the distribution $f(v)$ is known.

The utility function of venture investor with a risk aversion is defined as following piecewise linear function [14]:

$$
\mathrm{u}(X)=\left\{\begin{array}{c}
\left(X-V_{0}\right), X \geq V_{0} \\
\lambda\left(X-V_{0}\right), \quad X<V_{0}
\end{array}\right.
$$

Where $\lambda>1$ is the loss aversion coefficient, $\mathrm{X}$ is the final value of the investment portfolio, and $V_{0}$ is the reference point for profit and loss. Formula (1) shows that at the reference point attachment, the slope of loss is greater than the slope of profit, namely venture investor is more sensitive to the same amount of loss than the same amount of profit, and the greater of $\lambda$ the greater degree of disgust for loss.

Using $\mathrm{Z}$ as a set of feasible portfolio that satisfy a given constraint, if the venture investor can observe the real value $v$ of the project at the time of investment decision, then the optimal portfolio $\mathrm{z}(v)$ will be determined by solving following optimization problem:

$$
\mathrm{z}(v)=\arg \max _{z \in Z} u(z v)
$$

Where $\mathrm{u}(*)$ is the risk aversion utility function of venture investor that defined by formula (1).

However, venture investors do not know the future real value of these projects at the moment of making investment decisions, and usually only get an estimate of $v^{E}=\left[v_{1}^{E}, v_{2}^{E}, \cdots, v_{m}^{E}\right]^{T}$. Assume that these estimates values are an implementation value of a random variable
$\left(V^{E} \mid V\right) \sim f\left(v^{E} \mid v\right) \quad$ with a known density function $f\left(v^{E} \mid v\right)$. Further, it may be assumed that this estimate is conditional unbiased, that is, $E(V \mid V=v)=\int_{-\infty}^{+\infty} v_{i}^{E} f\left(v_{i}^{E} \mid v\right) d v_{i}^{E}=v_{i}$. If venture investors choose investment project based on these estimates $v^{\mathrm{E}}$, the optimal portfolio $z\left(v^{E}\right)$ can be obtained by solving the following optimization problem:

$$
z\left(v^{E}\right)=\arg \max _{z \in Z} u\left(z v^{E}\right)
$$

This paper points out that investment decisions that directly based on estimated value $v^{E}$ may lead to the selection of a non-optimal portfolio without considering the uncertainties contained in distribution functions $f(v)$ and $f\left(v^{E} \mid v\right)$. For example, considering portfolio decision problem with 12 alternatives $\mathrm{P}_{1}, \ldots, \mathrm{P}_{12}$, the real value of these projects is the realization value of independent and identically distributed random variable $\mathrm{V}_{\mathrm{i}} \sim \mathrm{N}\left(10,4^{2}\right), \mathrm{i}=1, \ldots, 12 . \quad\left(V_{i}^{E} \mid V_{i}=v_{i}\right)=$ $v_{i}+\Delta_{i}$, and $\Delta_{i} \sim N\left(0,1^{2}\right), \mathrm{i}=1, \ldots, 6$, as it is known that projects $\mathrm{P}_{1}$ to $\mathrm{P}_{6}$ are traditional projects and their future performance can be obtained with a relatively accurate estimate. On the other hand, projects $\mathrm{P}_{7}$ to $\mathrm{P}_{12}$ are novel "radical" projects, their value is difficult to obtain a reliable estimate, the corresponding model is $\left(\mathrm{Vi}^{\mathrm{E}} \mid \mathrm{V}_{\mathrm{i}}=\mathrm{v}_{\mathrm{i}}\right)=\mathrm{v}_{\mathrm{i}}+\Delta_{\mathrm{i}}$, where $\Delta \mathrm{i} \sim \mathrm{N}\left(0,5^{2}\right), \mathrm{i}=7, \ldots, 12$. As constrain of the total investment budget, it is only possible to select 5 projects from these 12 projects to invest. In addition, in the model, take the loss aversion coefficient $\mathrm{r}=2.25$, profit and loss of the reference point selected for the evaluation of the total value of five projects $\mathrm{V}=50$.

First of all, using the Matlab software, from the $\mathrm{V}_{\mathrm{i}} \sim \mathrm{N}(10$, 42) to generate the real value of project $P_{7}, \ldots, P_{12}$ of a group of realization value $v_{\mathrm{i}}$ were $9.62,6.67,11.18,4.66,12.86,16.49$, $7.65,18.73,9.45$, according to the model (2), the best investment portfolio $z(v)$ is the choice of $\left\{\mathrm{P}_{4}, \mathrm{P}_{5}, \mathrm{P}_{6}, \mathrm{P}_{8}, \mathrm{P}_{11}\right\}$, and the total utility value $u(z(v) v)$ of the project is 23.53 .

On the other hand, a set of estimated values $V_{i}^{E}$ for generating items $\mathrm{P} 7$ to $\mathrm{P} 12$ from $\left(V_{i}^{E} \mid V_{i}=v_{i}\right)=v_{i}+\Delta_{i}$, $\Delta \mathrm{i} \sim \mathrm{N}(0,12)$ are $8.93,7.53,12.43,3.06,11.42,17.07$, a set of estimated values $V_{i}^{E}$ of the items $\mathrm{P}_{7}$ to $\mathrm{P}_{12}$ generated by $\left(V_{i}^{E} \mid V_{i}=v_{i}\right)=v_{i}+\Delta_{i}, \quad$ I to $\mathrm{N}(0,52)$ are 5.65, 22.18, 13.53, $14.02,20.72$, 13.58. Based on these estimates, the investment utility $z\left(v^{E}\right)$ obtained by solving the model (3) is the corresponding utility value $u\left(z\left(v^{E}\right) v^{E}\right)$ of $\left\{\mathrm{P}_{6}, \mathrm{P}_{8}, \mathrm{P}_{10}, \mathrm{P}_{11}\right.$, $\left.\mathrm{P}_{12}\right\}$ is 37.57 , and the total expost utility value $u\left(z\left(v^{E}\right) v\right)$ of the portfolio is 20.19 .

From this example it can be found that, (a) based on the estimated value $v^{\mathrm{E}}$, the ex post facto total utility value (20.19) of the project portfolio $\mathrm{z}\left(\mathrm{v}^{\mathrm{E}}\right)$ is lower than the total utility value achieved 23.53 by the optimal portfolio $\mathrm{z}(\mathrm{v})$; (b) portfolio $\mathrm{z}$ $\left(v^{\mathrm{E}}\right)$ contains "radical" projects $\mathrm{P}_{10}$ and $\mathrm{P}_{12}$, which are selected 
with higher estimates, but they are not selected by optimal portfolio $\mathrm{z}(\mathrm{V})$; (c) the total value of the portfolio $\mathrm{z}\left(\mathrm{v}^{\mathrm{E}}\right)$ is estimated to be (87.57), which is $24.8 \%$ higher than the actual value (70.19) which actually realized, so decision maker will experience disappointment after the decision-making.

Formally, this paper gives following theorem 1, the detailed proof process refers to the appendix.

Theorem 1 Assuming $\mathrm{V}^{\mathrm{E}}$ to be a conditional unbiased estimate of $\mathrm{V}$, then:

$$
E\left[u\left(z\left(V^{E}\right) V\right)-u\left(z\left(V^{E}\right) V^{E}\right)\right] \leq 0
$$

While $z\left(V^{E}\right)$ is the optimal solution of problem (3). Furtherly, assume $z(V)$ be to optimal solution of problem (2), if $\quad P\left(z(V) \neq z\left(V^{E}\right)\right)>0, \quad$ then $E\left[u\left(z\left(V^{E}\right) V-\right.\right.$
$\left.u\left(z\left(V^{E}\right) V^{E}\right)\right]<0$.

Theorem 1 shows that, the total utility value actually achieved by the portfolio $z\left(V^{E}\right)$ does not exceed its previously estimated utility value in average. Moreover, if the probability of selecting "wrong" projects (unless entirely accurate, otherwise it is always) is greater than zero, the utility value of the selected portfolio based on the previous estimate is actually utility value $u\left(z\left(V^{E}\right) V\right)$, the expected interval between estimated utility value $u\left(z\left(V^{E}\right) V^{E}\right)$ combined with the project is strictly less than zero. In particular, even if the estimate of true value of the project is unbiased, the utility value of the portfolio chosen afterwards will be systematically overestimated because the items whose value is overvalued are more likely to be selected, investors will experience disappointment after the decision. Moreover, the higher uncertainty of prior estimates on true value of the project, the greater disappoints at end of investment period.

\section{Bayesian Modeling of Uncertainty in Project Portfolio}

Smith et al. [3-4, 12] found that, similar to problem of selecting only one scenario from multiple alternatives, the choice of project portfolio in a risk environment, the disappointment of investor decision-making can be achieved by applying Bayesian method. The modeling is mitigated by correcting estimated value of the project value.

In particular, given the estimated value $\mathrm{V}^{\mathrm{E}}$ of a given project, the Bayesian rule $f\left(v \mid v^{E}\right) \propto f(v) f\left(v^{E} \mid v\right)$ can be applied from prior distribution $f(v)$ and the likelihood distribution $f\left(v^{E} \mid v\right)$ and obtain posterior distribution $f\left(v \mid v^{E}\right)$ of the project value $v$. Furtherly, given the estimated value $v^{E}$, the optimal portfolio probability value $P\left(z_{i}(V)=1 \mid V^{E}=v^{E}\right)$ of project $i$ or the expected value of project $i$ can be calculated by using the posterior distribution $f\left(v \mid v^{E}\right)$. Thus, the posterior distribution can be used to construct a portfolio optimization problem with the goal of maximizing the expected utility of portfolio value.

Given value of $v^{E}$, investor's decision-making problem is to choose portfolio $\mathrm{z}$, maximizing the loss of aversion function $u\left(z E\left[V \mid V^{E}=v^{E}\right]\right)$. Therefore, according to the project's pre-estimated value $v^{E}$, following formula can be used:

$$
v B i=E\left[v_{i} \mid v^{E}=v^{E}\right]=\int_{-\infty}^{+\infty} v_{i} f\left(v_{i} \mid v^{E}\right) d v_{i}
$$

Calculate and get Bayesian estimate $v^{B}=\left[v_{1}^{B}, v_{2}^{B} \cdots v_{m}^{B}\right]^{T}$. The above formula (4) shows that Bayesian estimate of true value of the project $i$ is actually the expected value of posterior distribution $f\left(v_{1}^{B} \mid v^{E}\right)$.

Based on Bayesian estimate $v^{B}$, the portfolio that maximizes desired utility of venture investors can be determined by following optimization issues:

$$
z\left(v^{B}\right)=\arg \max _{z \in Z} u\left(z E\left[v \mid v^{E}=v^{E}\right]\right)=\arg \max _{z \in Z} u\left(z v^{B}\right)
$$

Continue to examine the 12 projects of $\mathrm{P}_{1}, \ldots, \mathrm{P}_{12}$ in section 2 , using the real value $v_{i}$ and the estimated value $v_{i}^{E}$ of the 12 projects that generated before, the future value of these projects can be calculated according to formula (4), the estimated values of the Bayes $v_{i}^{B}$ are 8.99, 7.68, 12.29, 3.47, $11.34,16.65,8.30,14.75,11.38,11.57,14.18,11.40$. Based on these Bayesian estimates of projects $\mathrm{P}_{1}, \ldots, \mathrm{P}_{12}$, and assuming that the model parameters and constraints are the same as in section 3, the optimal portfolio $z\left(v_{i}^{B}\right)$ obtained from solution model (5) is $\left\{\mathrm{P}_{3}, \mathrm{P}_{5}, \mathrm{P}_{6}, \mathrm{P}_{8}, \mathrm{P}_{10}, \mathrm{P}_{11}\right\}$, and the total utility value $u\left(z\left(v^{B}\right) v\right)$ is 21.13 . This indicates that total utility value (21.13) of the portfolio $u\left(v^{B}\right)$ based on Bayesian estimate based on model (5) is higher than the investment portfolio $z\left(v^{E}\right)$ directly based on pre-estimated value $v_{E}$, the total utility value (20.19).

Furthermore, in order to examine the performance of portfolio optimization model (5), in equation (4), this paper utilizes random variable: $V_{E}$ instead of the observed estimate $v_{E}$, and define the Bayes value of each project by following formula, $V_{i}^{B}=E\left[V_{1}, V_{2}^{B}, \ldots, V_{m}^{B}\right]^{T}$ (random variable):

$$
V_{i}^{B}=E\left[V_{i} \mid V^{E}\right]=\int_{-\infty}^{+\infty} v_{i}^{E} f\left(v_{i}^{E} \mid v\right) d v_{i}^{E}=v_{i}
$$

In this paper, it is pointed out that, under fairly general assumptions, the post-utility value of portfolio that based on Bayesian estimate $v^{\mathrm{B}}$ will be at least as much as post-utility value realized directly based on pre-estimated value $v^{\mathrm{E}}$. Formally, this paper proves the following theorem 2.

Theorem 2 assuming the meaning of $\mathrm{V}^{\mathrm{E}}, \mathrm{V}$ and $\mathrm{z}\left(\mathrm{V}^{\mathrm{E}}\right)$ as shown in theorem 1 , then:

$$
E\left[u\left(z\left(V^{E}\right) V\right)-u\left(z\left(V^{B}\right) V\right)\right] \leq 0
$$


Among them, VB is given by formula (6), and $z\left(V^{B}\right)$ is the optimal solution of model (5). Furthermore, if the probability that $z\left(v^{E}\right) \neq z\left(v^{B}\right) \quad$ occurs is greater than 0 , then $E\left[u\left(z\left(v^{E}\right) V\right)-u\left(z\left(v^{B}\right) V\right)\right]<0$. And:

$$
E\left[u\left(z\left(V^{E}\right) V\right)-u\left(z\left(V^{B}\right) V\right)\right]<0
$$

This is an intuitive result, because according to model (5), $z\left(v^{B}\right)$ maximizes the expected utility of the portfolio. Moreover, the Bayesian estimate of $z\left(v^{B}\right)$ based on Bayesian estimation will result in a strictly higher utility if

Bayes is used to estimate the probability that has a nonzero probability that leads to a different investment portfolio than directly using of the estimated value $z\left(v^{B}\right)$.

In general, there is no closed expression for posterior distribution of project value. However, a closed analytical expression for Bayesian estimation can be obtained if the distribution of true value of the project and the distribution of the estimate is a conjugate distribution $[3,12]$. For example, assume that true value of the project and the estimated value are subject to a self-conjugate normal distribution, so for each project $\mathrm{i}$ there are: actual value: $V_{i}=\mu_{i}+E_{i}, E_{i} \sim N\left(0, \sigma_{i}^{2}\right)$ estimated value: $\left(V_{i}^{E} \mid V_{i}=v_{i}\right)=v_{i}+\Delta_{i}, \quad \Delta_{i} \sim N\left(0, \tau_{i}^{2}\right)$

Thus, Bayesian estimate of formula (4) becomes:

$$
v_{i}^{B}=\alpha_{i} v_{i}^{E}+\left(1-\alpha_{i}\right) \mu_{i}
$$

among them: $\alpha_{i}=\left(1+\frac{\tau_{i}^{2}}{\sigma_{i}^{2}}\right)^{-1}$

Therefore, it is not difficult to find from formula (7) that for the normal distribution, the Bayesian estimate of project value depends on prior mean $\mu_{i}$ and observed pre-estimated value $v_{i}^{E}$, which is weighted average of $\mu \mathrm{i}$ and $v_{i}^{E}$, depending on variance ratio $\tau_{i}^{2} / \sigma_{i}^{2}$. If variance $\tau_{i}^{2}$ of estimated error $\Delta_{\mathrm{i}}$ is larger than prior variance $\sigma_{i}^{2}$, then the weight $\alpha_{\mathrm{i}}$ of estimated value $v_{i}^{E}$ is small, namely a priority mean value $\mu \mathrm{i}$ is catching more attention at this time. On the other hand, if variance $\tau_{i}^{2}$ of estimated error $\Delta_{\mathrm{i}}$ is smaller than prior variance $\sigma_{i}^{2}$, then $\alpha_{i}$ will be close to 1 , reflecting relatively reliable information provided by estimated value $v_{i}^{E}$ on how much value the project $i$ will achieve afterwards ${ }^{[3,12]}$.

In practice, in order to describe a normal a priori, decision maker needs to determine prior mean $\mu_{i}$ and variance $\sigma_{i}^{2}$. If venture investors have location and scale information about the value of project $i$, they can match these $\mu_{i}$ and square $\sigma_{i}^{2}$. According to the thumb rule, the vast majority of data points $(99.7 \%)$ of probability distribution are located within the interval $\mathrm{I}=\left[\mu_{i} \pm 3 \sigma_{i}\right]$. Thus, if venture investor can determine the reasonable upper bound and the lower bound of $\mathrm{v}_{i}$, priori mean $\mu_{i}$ and variance $\sigma_{i}^{2}$ can be determined, so that these upper bounds and lower bounds can correspond to the end points of interval I [19].

In some cases, prior distribution $f(v)$ may not be normal. For example, the value of the project may be asymmetric, and most of the data points of its probability distribution focus on smaller values. For this case, a probable prior distribution is an asymmetric triangular distribution [20], which simply estimates three parameters of $\mathrm{v}_{\mathrm{i}}$, namely the maximum, the minimum, and the most probable (the plural). In addition, venture investor can also estimate the percentile of the value $v_{i}$ of each project $i$, and then convert the resulting step function into a continuous distribution function by applying kernel smoothing method [21].

According to Vilkkumaa et al. [12], if the estimated error is additive, the project is specific and follows the normal distribution with mean value is 0 , then the likelihood function corresponds to the estimate of each project $\mathrm{i}(\mathrm{i}=1, \ldots, \mathrm{m})$ error variance $\tau_{i}^{2}$. In order to estimate $\tau_{i}^{2}$, decision maker can specify a maximum range so that he should expect, for example, that at least the value of project valuation of $\tau_{i}^{2}$ is within this range, then $\tau_{i}^{2}$ can be estimated from this range. On the other hand, if the project is evaluated by a number of experts, the variance of expert's evaluation of project valuation can be interpreted as $\tau_{i}^{2}$. This method has been advocated by some scholars [22]. Moreover, since this approach does not require expert to evaluate the project to directly determine $\tau_{i}^{2}$, it is possible to overcome the unaudited tendency of the generally observed individual independence to assess the project valuation ${ }^{[22]}$.

It can be shown that there is no need to make any specific assumptions (eg, normal distributions) for prior distribution $f(v)$ and the likelihood distribution $f\left(v^{E} \mid v\right)$ or relevant constraint of the problem, and Bayesian estimate can eliminate the selected expected interval between expected utility value of the portfolio and expected utility value. In this paper, the following theorem 3 is given.

Theorem 3 assume the meaning of $\mathrm{V}, \mathrm{V}^{\mathrm{E}}, \mathrm{V}^{\mathrm{B}}$, and $\mathrm{z}(\bullet)$ is as the same that shown in theorem 2:

$$
E\left[u\left(z\left(v^{B}\right) V\right)-u\left(z\left(v^{B}\right) v^{B}\right) \mid V^{E}=v^{E}\right]=0
$$

It is right for all $\mathrm{v}^{\mathrm{E}}$ established, and there are:

$$
E\left[u\left(z\left(v^{B}\right) V\right)-u\left(z\left(v^{B}\right) v^{B}\right)\right]=0 .
$$

Theorem 3 shows that expected interval between final expected utility value and expected utility value based on Bayesian estimate $v^{B}$ is zero, based on the portfolio $z\left(v^{B}\right)$ determined by optimization model (5). Even in individual cases, Bayesian estimation tends to reduce the degree of disappointment after decision-making because extreme Bayes correction value $v_{i}^{B}$ is less likely to occur than extreme estimate $v_{i}^{E}$. 
In practical applications, if priori distribution and likelihood distribution are conjugate, the Bayesian rule can be used to obtain analytic expression of the posterior distribution of each project $i$ [19]. If the prior distribution and likelihood distribution are not conjugate, then posterior distribution needs to be approximated. $v_{i}(l)(l=1, \ldots, L)$ is discretized for the distribution of $\mathrm{Vi}$, and then corresponding to each of the L-sample values $v_{i}(l)(l=1, \ldots, L)$ from prior distribution $v^{E}(l, k), \mathrm{k}=1, \ldots, \mathrm{K}$ from likelihood distribution of $V^{E} \mid V_{i}=v_{i}(l)$. Thus, posterior distribution corresponding to initial estimate $v^{E}$ can be obtained by marginal distribution function caused by $V^{E}=v_{E}$ and normalized in discrete joint distribution. If discretization is sufficiently dense, the value of alternative projects is distributed independently, and the method works well. However, if the value between the alternatives and the estimates are dependent, it is possible to extract a sufficiently large amount of data at each point of a dense multidimensional grid, which may require considerable computational effort. Wei Laisheng et al. [19] and Rup-pert et al. [23] give the simulation and numerical integration strategies.

\section{Risk Portfolio Optimization Model That Based on Loss Aversion}

There are $m$ alternative risk projects, the total investment of venture investors is $S_{0}$, and the investment amount of i-th risk project is $s_{i}$. The total capital required for $m$ projects is: $S_{1}=\sum_{i=1}^{m} s_{i}$, but total investment budget $S_{0}<S_{1}$, namely venture investors can only choose some of the projects to invest. If you choose to invest in $\mathrm{i}$-th project, then let $z_{i}=1$, otherwise let $z_{i}=0, i=1, \ldots m$. That is, once venture investors determine to invest project $i$, you must invest $S_{i}$, only to decide whether to invest, without the investment amount in decision-making.

It is further assumed that benefit (value) available for investment in risk project $i$ is $V_{i}$, so project portfolio optimization model that takes into account of psychological characteristics of loss aversion of venture investors can be described as:

$$
\begin{gathered}
\max E u=\sum_{i=1}^{m} z_{i} V_{i} \\
\text { s.t. }\left\{\begin{array}{c}
\sum_{i=1}^{m} s_{i} z_{i} \leq S_{0} \\
z_{i}=0 o r 1, i=1,2, \cdots m ;
\end{array}\right.
\end{gathered}
$$

Where utility function $u(\bullet)$ is piecewise linear function defined by model (1).

Since it is often difficult to obtain an analytic expression of objective function in model (8), Monte Carlo simulation can be considered for solving problems $[18,24]$. The basic idea of this method is to use random number generation algorithm to generate random number representing the yield of project according to statistical characters of distribution function, mean value and variance of random variable, and convert problem (8) into deterministic optimization problem, then obtains approximate solution of original problem by solving the algorithm of deterministic optimization problem. The specific solution to problem (8) is given below.

According to the mean value $\mu_{i}$ and the standard deviation $\sigma_{i}$ of project valuation $V_{i}$, the Monte Carlo algorithm can be used to obtain corresponding samples $v^{l}, \ldots, \quad v^{N}$, where $v^{j}=\left(v_{1}^{j}, v_{2}^{j}, \ldots, v_{m}^{j}\right)^{T}, j=1, \ldots, N, N$ is the sample size, so the objective function of model (8) can be approximated as follows:

$$
\begin{gathered}
u(z)=\frac{1}{N} \sum_{j=1}^{N} u\left(X^{j}, V_{0}\right) \\
=\frac{1}{N} \sum_{j=1}^{N}\left[\left(\sum_{i=1}^{m} z_{i} v_{i}^{j}-V_{0}\right)^{+}-\lambda\left(\sum_{i=1}^{m} z_{i} v_{i}^{j}-V_{0}\right)^{-}\right]
\end{gathered}
$$

Where $(\mathrm{t})^{+}$represents the maximum value of 0 and $\mathrm{t}$, and $(t)^{-}$represents the maximum of 0 and $-t$. Using auxiliary variables $y^{k}$ to substitute $\left(\sum_{i=1}^{m} z_{i} v_{i}^{j}-V_{0}\right)^{+}$, using $\xi^{j}$ to substitute $\left(\sum_{i=1}^{m} z_{i} v_{i}^{j}-V_{0}\right)^{-}$, and using the below equation:

$$
X_{j}-V_{0}=\left(X^{j}-V_{0}\right)^{+}-\left(X^{j}-V_{0}\right)^{-}
$$

The model (8) can be transformed into following linear mixed integer programming problem:

$$
\begin{gathered}
\max \bar{u}_{N}(z)=\frac{1}{N} \sum_{i=1}^{N}\left(y^{j}-\lambda \xi^{j}\right) \\
\text { s.t. }\left\{\begin{array}{c}
y^{j}-\xi^{j}=\sum_{i=1}^{m} z_{i} v_{i}^{j}-V_{0} \\
\sum_{i=1}^{m} s_{i} z_{i} \leq S_{0} \\
z_{i}=0 \text { or } 1, i=1,2, \cdots, m \\
y^{j}-\xi^{j} \geq 0, j=1,2, \cdots, N
\end{array}\right.
\end{gathered}
$$

In addition, in order to examine the impact of venture investor's loss aversion on portfolio decision-making, this paper also solves following portfolio optimization model for maximizing project portfolio total expected value [12]: 


$$
\begin{gathered}
\max \text { value }=\frac{1}{N} \sum_{j=1}^{N} \sum_{i=1}^{m} z_{i} v_{i}^{j} \\
\text { s.t. }\left\{\begin{array}{c}
\sum_{i=1}^{m} s_{i} x_{i} \leq S_{0} \\
z_{i}=0 \text { or } 1, i=1,2, \cdots, m
\end{array}\right.
\end{gathered}
$$

According to models (10) and (11), if investment objective of venture investor is expected total value of portfolio, the expected value of portfolio at end of investment period is $E(z V)$, and when venture investor is risk aversion, the objective function of investment portfolio is $E\left(z V-V_{0}\right)^{+}-$ $\lambda E\left(z V-V_{0}\right)^{-}$. By comparing these two objective functions, it can be seen that under same budget constraint, the loss aversion coefficient $\lambda$ of venture investor is the key factor that causes the target of model (10) and model (11) to be different under the same budget constraint. That is, the objective function in model (8) reflects the pleasure of the same amount of profit when the venture investor is faced with a certain amount of loss. Therefore, the model established in this paper embodies the loss psychological characteristics of the loss of venture investors, and the model in literature [12] reflects the risk of venture investors in decision-making.

\section{Numerical Examples}

\subsection{An Analysis of the Impact of Loss Aversion on Portfolio Selection}

In order to test the effectiveness of Bayesian modeling in practical application, this paper applies Monte Carlo stochastic simulation to generate the value data of alternative projects and calculate the value of Bayesian model in portfolio optimization model (10) and the uncertainty of project value estimation, and calculating the model (10) and model (11) of optimal portfolio.

Considering a venture capital firm with 10 risk projects $\mathrm{A}, \ldots, \mathrm{J}$ for its investment choice [12], the investment amount required for these projects were $9,3,4,6,5,7,12,8,2,1$ (unit: million). The total amount fund of investment firm is \$ 25 million, so it is only possible to select some of projects from these risk projects to invest. Assuming that the real value $v_{i}$ of these risk projects at end of the investment period is the realization value of random variable $V_{i}=\mu_{i}+E_{i}, i=A, \ldots$, $J$, there are $\mu_{i}=10$ and $E_{i} \sim N\left(0,3^{2}\right)$. It is further assumed that projects $A$ to $D$ are traditional projects whose future values can be obtained with relatively accurate estimates. The estimates are generated by model $\left(V_{i}^{E} \mid V_{i}=v_{i}\right)=v_{i}+\Delta_{i}, \Delta \mathrm{i}$ $\sim \mathrm{N}(0,12)$. On the other hand, projects $\mathrm{E}$ to $\mathrm{J}$ are novel "radical" projects whose future values are more difficult to obtain by model $\left(V_{i}^{E} \mid V_{i}=v_{i}\right)=v_{i}+\Delta_{i}, \Delta \mathrm{i} \sim \mathrm{N}(0,2.82)$ generated. Applicate Matlab to generate 200 groups observations of $v_{i}$ and $\mathrm{v}_{i}^{E}$, and use formula (7) to calculate the corresponding $\mathrm{v}_{i}^{B}$.

The estimated value $v_{i}^{E}$ of 10 alternatives obtained by above method is substituted into model (10) and model (11) respectively with corresponding Bayes correction value $v_{i}^{B}$ $(\mathrm{m}=10, \mathrm{~N}=200)$. Take $\lambda=2.25, \mathrm{~V}_{0}=55$, the following table 1 gives the results of the solution.

Table 1. The Impact of Loss Aversion on Portfolio.

\begin{tabular}{llll}
\hline Portfolio model & Project selection results & Estimated total value & The total value achieved \\
\hline Model based on $v_{i}^{\mathrm{E}}(10)$ & $\mathrm{B}, \mathrm{D}, \mathrm{E}, \mathrm{H}, \mathrm{I}, \mathrm{J}$ & 64.02 & 62.60 \\
Model based on $v_{i}^{\mathrm{E}}(11)$ & $\mathrm{B}, \mathrm{C}, \mathrm{E}, \mathrm{H}, \mathrm{I}, \mathrm{J}$ & 64.50 & 63.28 \\
Model based on $v_{i}^{\mathrm{E}}(10)$ & $\mathrm{A}, \mathrm{B}, \mathrm{C}, \mathrm{E}, \mathrm{I}, \mathrm{J}$ & 63.34 & 64.13 \\
Model based on $v_{i}^{\mathrm{E}}(11)$ & $\mathrm{B}, \mathrm{C}, \mathrm{D}, \mathrm{E}, \mathrm{I}, \mathrm{J}$ & 63.35 & 63.88 \\
\hline
\end{tabular}

As can be seen from Table 1 above, the portfolio model based on loss aversion behavior (10) is not the same as the portfolio selected by risk-based neutral portfolio (11), which means that the loss of venture investors evasion of psychology has an important impact on its portfolio decision making. In addition, for both models, the total value $z\left(v^{E}\right) v$ of post-event project based on estimated value of the portfolio of $v_{i}^{E}$ is lower than the pre-estimate $z\left(v^{E}\right) v^{E}$, and Bayesian estimate can be used to improve the portfolio's total value, reduce the degree of disappointment after decision-making.

\subsection{An Analysis of the Impact of Project Estimated Uncertainty on Portfolio Selection}

This section will use an example to analyze the impact of uncertainty in project valuation on the degree of disappointment after decision making. The real value $v_{i}$ of these 100 projects is derived from standard normal distribution $\mathrm{N}(0,1)$, and their estimates $v_{i}^{E}$ are estimated by an additive zero mean error model (10) $v_{i}^{E}=v_{i}+\delta_{i}$ is generated, where the estimated error $\delta_{i} \sim N\left(0, \tau^{2}\right)$. The influence of the uncertainty of the project value estimation on the degree of disappointment after the decision is studied by taking different values of $\tau \in[0,1]$ for taking $\lambda=2.25$ and $V_{0}=0$.

The following figure 1 shows that when the standard deviation $\tau$ of estimated error changes, run Monte Carlo simulates 1000 times to solve average utility value $E u\left(z\left(V^{E}\right) V^{E}\right)$ estimated by the portfolio obtained by model (10) $E u\left(z\left(V^{E}\right) V\right)$, it is easy to see from figure 1 that the degree of disappointment after the decision is increased as standard deviation $\tau$ of estimated error $\delta_{\mathrm{i}}$ of the project value increases. It is that the greater the uncertainty in project estimates, not only makes it difficult for venture 
investors to identify projects that are of high real value, but also make it more likely that venture investors will choose those projects with high estimates, the greater the disappointment, which is also the numerical simulation of the theorem 1. For example, in figure 1 , when $\tau=0.8$, the selected portfolio estimates the average utility value of 22.22 , which is $64.23 \%$ higher than the average utility value 13.53 .

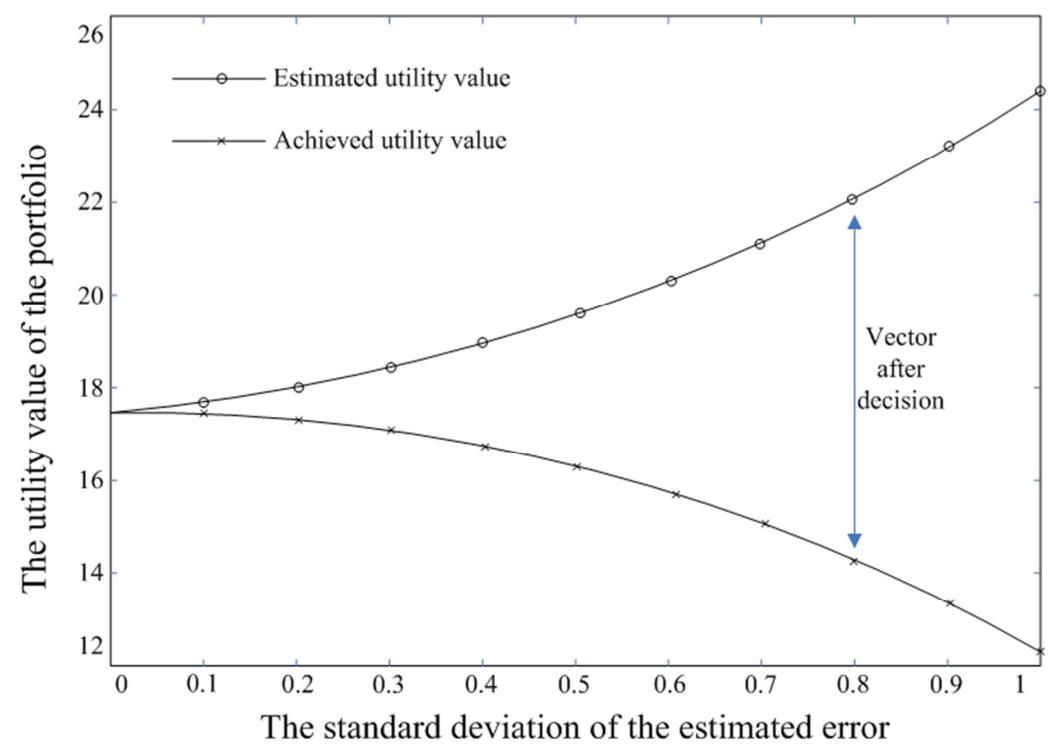

Figure 1. Estimated error of the standard deviation increases when the model (10) of the portfolio corresponds to the expected utility estimate and the implementation value.

At the same time, in order to test whether the portfolio selected based on Bayes correction value can eliminate the expected interval between expected utility value and its expected utility value, the following figure 2 shows the criteria for estimated error of the project value Monte Carlo simulation is performed 1000 times, and the Bayes correction value $v_{i}{ }^{B}$ calculated by (7) is used instead of $v_{i}$ in model (10) to solve the average utility value of the portfolio obtained by model (10) $E u\left(z\left(V^{B}\right) V^{B}\right)$ and the effect of the average utility value $E u\left(z\left(V^{B}\right) V\right)$. It is easy to see from figure 2 that Bayesian correction of the prior estimate of the project value can eliminate the disappointment of venture investor's decision, thus supporting the conclusion from theorem 3 .

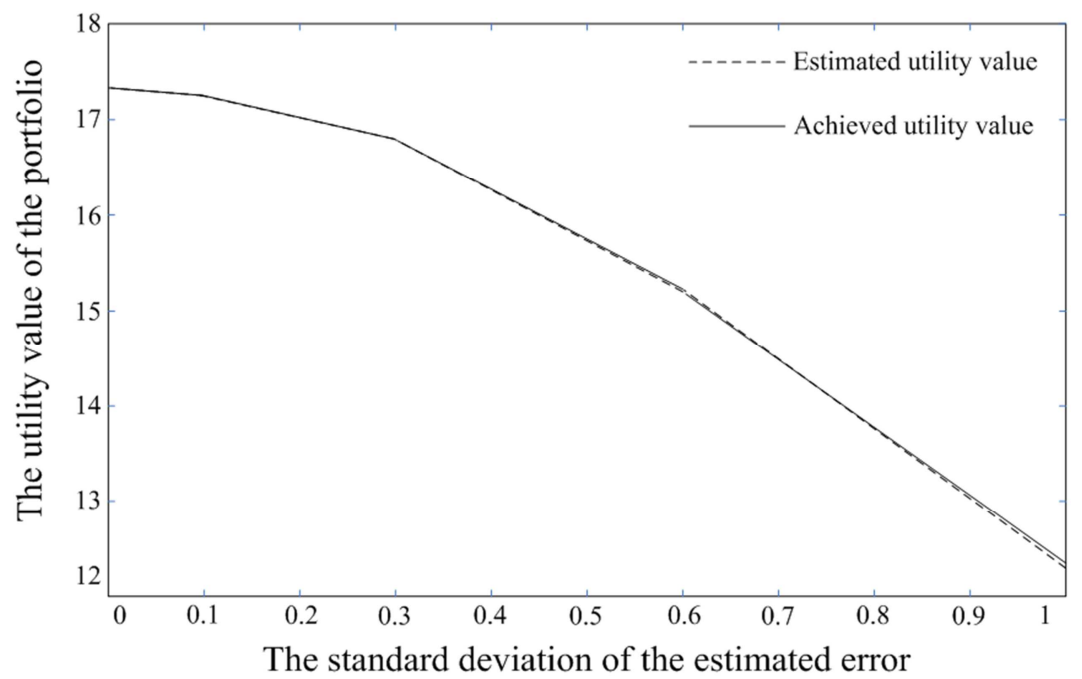

Figure 2. Estimated utility values and expected utility values for the portfolio based on the Bayesian estimate.

\subsection{Analysis on the Impact of Bayes Modeling on Portfolio Performance}

In order to further examine the role of Bayes modeling of uncertainty in project valuation for portfolio performance, it is still considered to select 10 projects from 100 alternative projects to invest in the real value of the 100 projects from normal distribution $N(5,18)$. These items are divided into two subprojects, in which the value of the first type of project has a small estimated error variance $\Delta_{\mathrm{i}} \sim N\left(0,4^{2}\right)$, while the 
second category has a larger estimated error variance $\Delta \mathrm{i} \sim N(0$, $3^{2}$ ). In model (10), let $\lambda=2.25, V_{0}=50$, the following figure 3 shows that when the number of items with larger estimated error variance increases, the pre-estimated value $v_{i}{ }^{E}$ based on the project value is Bayes recommended estimate, $\mathrm{v}_{\mathrm{i}}{ }^{\mathrm{B}}$, solves posterior utility values achieved by model (10) by portfolio.
It is easy to see from figure 3 that optimal portfolio based on Bayesian estimate $v_{i}^{B}$ has a higher practical utility value than the portfolio chosen directly based on estimated value $v_{i}^{E}$, which in fact further supports the rationality of theorem 2.

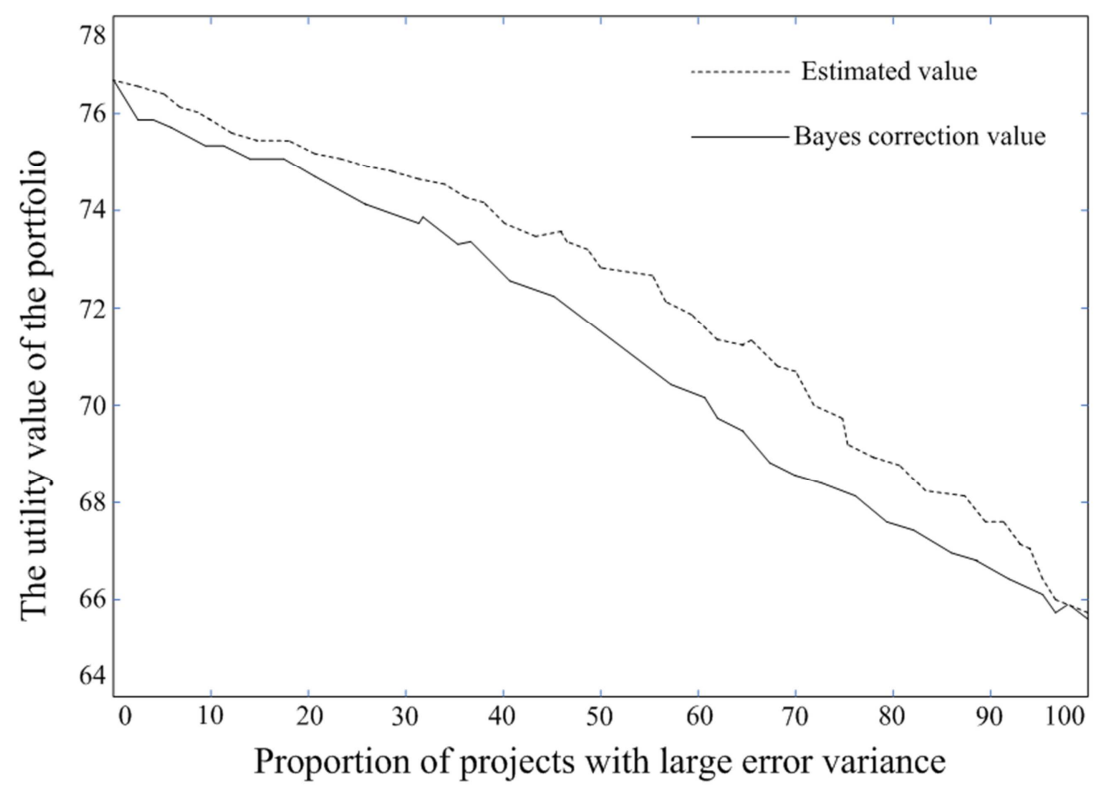

Figure 3. Shows the performance of the portfolio based on the direct estimate and the Bayesian estimate.

\section{Conclusion}

Traditional portfolio problem is based on Von-Neumann's theory of expectation utility. A large number of empirical studies have found that investors are deviating from expected utility theory when making investment decisions, not necessarily completely disgusted with risk, and often show such as loss disgust, excessive self-confidence and other irrational behavior. The study of behavioral decision theory makes people to realize that investor's behavior plays an important role in asset allocation. This paper constructs a portfolio optimization model of risk project based on loss avoidance decision-making behavior from perspective of behavioral finance. Considering the uncertainties in the future value of risk projects, Bayesian modeling is used to revise the prior value estimates of risk projects. It is found that Bayesian correction estimates tend to give more accurate estimates of project value. At the same time, based on Monte Carlo stochastic simulation algorithm, the constructed portfolio model is transformed as easy linear integer programming problem. The portfolio model based on loss aversion is compared with risk-based portfolio model, and the risk is found. Investor's loss to circumvent psychology has an important impact on their investment decisions. In addition, this paper also theoretically proves, for any prior distribution and likelihood distribution, compared with the investment based on pre-estimated value, Bayesian modeling of the uncertainty of project value estimates and Bayes correction value is used to construct a portfolio that can help venture investors choose to be able to provide a higher post-utility value of portfolio and reduce the potential disappointment afterdecision-making, eliminating the estimated value of previous utility value between expected intervals. Finally, the theoretical results are verified by Monte Carlo simulation.

It should be noted that the analysis of this paper is known based on prior distribution $f(v)$ and likelihood distribution $f\left(v^{E} \mid v\right)$ of the assumed project value. Since project portfolio is a recurring activity for most of venture capital firms, it is possible to have historical data on project valuation and valuation estimates so that these historical data can be used to estimate the prior distribution and likelihood distribution. However, in venture capital practice, certain risk projects usually do not have or have only a small amount of historical information, and if venture investor does not have any prior information about the alternative, then a non-informative prior method based on evaluation information to calculate posterior distribution. In addition, if prior distribution and likelihood distribution are conjugate, the closed expression of posterior distribution $f\left(v_{i} \mid v^{E}\right)$ of each project $i$ can be obtained by Bayes theorem. However, if prior distribution and likelihood distribution are not conjugate, then Bayes posterior distribution is determined to be calculated for high dimensional integrals. In order to reduce computational workload, the Markov Chain Mante Carlo (MCMC) method can be used to sample the prior distribution, and determine the discrete value of posterior distribution. Then the 
approximation is given by statistical inference based on discrete valuation $[19,23]$.

This paper only considers single-stage investment decision-making problem, and assumes that the investment cost of each project is determined. However, in actual investment activities, venture capital firms may adopt phased investment strategy according to the change of market environment in order to avoid or reduce risks, the project investment cost may also change over time. Therefore, we can further study the multi-stage portfolio problem that also considers the uncertainty of project value and cost. In addition, there is always a correlation between background risk and project risk in the process of project investment. How to build a multi-stage project investment decision model that takes into account both background and project risks is also worth of research questions.

\section{Appendix}

Proof of theorem 1:

For given $v$ and $v_{\mathrm{E}}$, there is:

$$
\begin{gathered}
u\left(z\left(v^{E}\right) v\right)-u\left(z\left(v^{E}\right) v^{E}\right) \leq u(z(v) v)-u\left(z\left(v^{E}\right) v^{E}\right) \\
\leq u(z(v) v)-u\left(z(v) v^{E}\right)
\end{gathered}
$$

Among them, the first inequality holds because $\mathrm{z}(\mathrm{v})$ is the optimal solution to problem (2), and the second inequality holds because $\mathrm{z}\left(v_{\mathrm{E}}\right)$ is the optimal solution to problem (3). Therefore, under the condition of $\mathrm{V}=v$, the distribution of the random variable $\mathrm{V}^{\mathrm{E}}$ is $f\left(v^{E} \mid v\right)$, and the expectation of (12) as follows:

$$
\begin{aligned}
& E\left[u\left(z\left(v^{E}\right) v\right)-u\left(z\left(V^{E}\right) V^{E}\right) V^{E} \mid V=v\right] \\
& \quad \leq E\left[u(z(v) v)-u\left(z\left(V^{E}\right) V^{E}\right) \mid V=v\right] \\
& \quad=u(z(v) v)-u\left(z\left(V^{E}\right)\right) \underbrace{E\left[V^{E} \mid V=v\right]}_{=v}=0
\end{aligned}
$$

Among them, the last equation is established because the assumptions on the value of the project estimates are unbiased estimates. Since (13) holds for all v, here can get: $E\left[u\left(z\left(V^{E}\right) V\right)-u\left(z\left(V^{E}\right) V^{E}\right)\right] \leq 0$.

In addition, the first inequality of (12) strictly holds for some $v$ and $v^{\mathrm{E}}$ if it is possible to choose a non-optimal item which means $P\left(z(V) \neq z\left(V^{E}\right)\right)>0$. Therefore, if the probability of occurrence of this event is positive, inequality (13) holds strictly for the corresponding v such that

$$
E\left[u\left(z\left(V^{E}\right) V\right)-u\left(z\left(V^{E}\right) V^{E}\right)\right]<0 .
$$

Proof of theorem 2:

For a given $v^{\mathrm{E}}$, the Bayes estimate $v^{\mathrm{B}}$ and the optimal solutions $z\left(v^{\mathrm{E}}\right)$ and $\mathrm{z}\left(v^{\mathrm{B}}\right)$ for both problems (3) and (5) are fixed, so the conditional expectation of $u\left(z\left(v^{E}\right) V\right)-u\left(z\left(v^{B}\right) V\right)$ is as follows:

$$
\begin{gathered}
E\left[u\left(z\left(v^{E}\right) V\right)-u\left(z\left(v^{B}\right) V\right) \mid V^{E}=v^{E}\right] \\
=u(z\left(v^{E}\right) \underbrace{E\left[V \mid V^{E}=v^{E}\right]}_{v^{B}})-u(z\left(v^{B}\right) \underbrace{E\left[V \mid V^{E}=v^{E}\right]}_{v^{B}}) \\
=u\left(z\left(v^{E}\right) v^{B}\right)-u\left(z\left(v^{B}\right) v^{B}\right) \leq 0
\end{gathered}
$$

The second equation is based on the definition of $v B$. The final inequality holds because $z\left(v^{B}\right)$ is the optimal solution to problem (5). Therefore, it can be obtained that $E\left[u\left(z\left(v^{E}\right) V\right)-u\left(z\left(v^{B}\right) V\right)\right] \leq 0$ by integrating $v^{\mathrm{E}}$.

If $z\left(v^{E}\right) \neq z\left(v^{B}\right)$ is true for some $v^{E}$, then for $v^{B}=E\left[V \mid V^{E}=v^{E}\right]$, here it can be obtained that as follows:

$$
u\left(z\left(v^{E}\right) v^{B}\right)-u\left(z\left(v^{B}\right) v^{B}\right)<0
$$

Therefore, inequality formula (14) holds strictly if $P\left(z\left(V^{E}\right) \neq z\left(v^{B}\right)\right)>0$, that is as follows:

$$
E\left[u\left(z\left(V^{E}\right) V\right)-u\left(z\left(v^{B}\right) V\right)\right]<0
$$

Proof of theorem 3:

For a given set of estimates $v^{\mathrm{E}}$, the corresponding Bayes estimate $v^{\mathrm{B}}$ and the optimal solution $z\left(v^{B}\right)$ of problem (5) are also fixed, and the conditional expectation of $u\left(z\left(v^{B}\right) V\right)-u\left(z\left(v^{B}\right) v^{B}\right)$ is as follows:

$$
\begin{gathered}
E\left[u\left(z\left(v^{B}\right) V\right)-u\left(z\left(v^{B}\right) v^{B}\right)\right] \mid V^{E}=v^{E}= \\
u(z\left(v^{B}\right) \underbrace{E\left[V \mid V^{E}=v^{E}\right]}_{=v^{B}}-u\left(z\left(v^{B}\right) v^{B}\right)=0
\end{gathered}
$$

Since $v^{\mathrm{B}}$ is deterministic, the first equation holds, and according to the definition of $v^{\mathrm{B}}$, the second equation also holds. Integrating of $v^{\mathrm{E}}$, here it can be obtained that: $E\left[u\left(z\left(V^{B}\right) V\right)-u\left(z\left(V^{B}\right) V^{B}\right)\right]=0$.

\section{References}

[1] Smidt S. A Baysian analysis of project selection and of post audit evalutions [J]. Journal of Finance, 1979, 34 (3):675-689.

[2] Fliedner T, Liesio J. Adjustable robustness for multi-attribute project portfolio selection [J]. European Journal of Operational Research, 2016, 252 (3):931-946.

[3] Smith J E, Winkler R L. The Optimizer's Curse: Skepticism and post-decision surprise in decision analysis $[\mathrm{J}]$. Management Science, 2006, 52 (3):311-322.

[4] Chen M, Dyer J. Inevitable disappointment in projects selected on the basis of forecasts [J]. SPE Journal, 2009, 14 (2):216-221.

[5] Zhang Qun, Huang Xiaoxia, Zhang Chao. A mean-risk index model for uncertain capital budgeting $[\mathrm{J}]$. Journal of the Operational Research Society, 2015, 66 (5):761-770. 
[6] Hall N G, Long Zhuoyu, Qi Jin, et al. Managing underperformance risk in project portfolio selection [J]. Operations Research, 2015, 63 (3):660-675.

[7] Xu Weijun, Luo Weiqiang, Zhang weiguo. Multiple Portfolio Decision Models Considering Bankruptcy Risk Constraints [J]. Operations and Management, 2013, 22 (6):92-98.

[8] Yu Chao, Fan Zhiping. Selection method of capital project under considering the decision-makers regret to avoid the venture [J]. Chinese Management Science, 2016, 24 (6):29-37.

[9] Jacquier E, Polson N. Bayesian methods in finance [M].//Geweke J, Koop G, Van Dijk H. The Oxford handbook of Bayesian econometrics, Oxford, England: Oxford university press, 2011.

[10] Diris B, Palm F, Schotman P. Long-term strategic asset allocation: An out-of-sample evaluation [J]. Management Science. 2015, 61 (9):2185-2202.

[11] Yang Lei, Zhao Jiuru. Selection and Evaluation of New Product Development Risk Decision Research [J]. Operations and Management, 2015, 24 (3):127-133.

[12] Vilkkumaa E, Liesio J, Salo A. Optimal strategies for selecting project portfolios using uncertain value estimates [J]. European Journal of Operational Research, 2014, 233 (3):772-783.

[13] Kahneman D, Tversky A. Prospect theory: An analysis of decision under risk [J]. Econometrica, 1979, 47 (2):263-291.

[14] Barberis N, Huang Ming, Santos T. Prospect theory and asset prices $[\mathrm{J}]$. The Quarterly Journal of Economics, 2001, 116 (1):1-53.

[15] Fulga C. Portfolio optimization under loss aversion [J]. European Journal of Operational Research, 2016, 251 (1):310-322.

[16] Jin Xiu, Wang Jia, Gao Yin. Optimal Asset Allocation and Empirical Study Based on Dynamic Loss Aversion Portfolio Model [J]. Chinese Management Science, 2014, 22 (5):16-23.

[17] Wang Jia, Jin Xiu, Wan Yin. A Robust Portfolio Model Based on Loss Aversion and Fuzzy Aversion [J]. Systems Engineering Theory and Practice, 2016, 36 (2):288-296.
[18] Zhang Maojun, Nan Jiangxia, Yuan Gonglin, etal. Investment Decision Model Based on Loss Averse Fund Managers [J]. Chinese Journal of Management, 2014, 28 (4):118-124.

[19] Wei Laisheng, Zhang Weiping. Bayesian analysis [M]. University of Science and Technology of China Press, 2013.

[20] William T S, Thomas A P, Douglas N F. The triangular density to approximate the normal density: Decision rules-of-thumb $[\mathrm{J}]$. Reliability Engineering and System Safety, 2003, 82 (3):331-341.

[21] Li Qi, Raccine J. Nonparametric Econometrics: Theory and Practice [M]. Ye A-Zhong, Wu Xiangbo translation, Beijing: Peking University Press, 2015.

[22] Van den Steen E. Overconfidence by Bayesian-rational agents [J]. Management Science, 57 (5):884-896.

[23] Ruppert D, Matteson D S. Bayesian data analysis and MCMC $[\mathrm{M}] / /$ Ruppertp, Matteson D S. Statistics and data analysis for financial engineering, Springer Texts in Statistics, 2015:581-644.

[24] Shapiro A, Dentcheva D, Ruszczynski A. Lectures on stochastic programming: Modeling and theory $[\mathrm{M}]$. 2nd Edition, Philadephia:SIAM, 2014.

[25] Jose V R R. Assessing probability distributions from data $[\mathrm{M}] / /$ Conhran J J. Wiley encyclopedia of operations research and management science, New York: John Wiley and Sons, 2010:183-190.

[26] Price H J, Manson A R. Uninformative priors for Bayes theorem $[\mathrm{C}] / /: 21 \mathrm{st}$ International Workshop on Bayesian Inference and Maximum Entropy Methods in Science and Engineering, Battimore, M D, Augest 4-9, 2002.

[27] Zhang Yao, Guan Xin, Sun Yang, etal. Project Investment Decision Under Considering Background Risk [J]. Chinese Management Science, 201, 24 (9):71-80. 